\title{
CAPÍTULO 30: RESÍDUOS AGRÍCOLAS COMO FONTES DE PREBIÓTICOS PARA APLICAÇÃO BIOTECNOLÓGICA: UMA BREVE REVISÃO
}

\section{CHAPTER 30: AGRICULTURAL WASTE AS PREBIOTIC SOURCES FOR BIOTECHNOLOGICAL APPLICATION: A BRIEF REVIEW}

\author{
Nairane da Silva Rosa-Leão ${ }^{1}$; Quésia Jemima da Silva ${ }^{2}$; Beatriz de Aquino Marques da Costa ${ }^{3}$, Vagne \\ de Melo Oliveira ${ }^{4}$ e Ana Lúcia Figueiredo Porto ${ }^{5}$
}

\begin{abstract}
Resumo
Resíduos agrícolas são considerados algumas das principais matérias-primas possíveis para obtenção de produtos biológicos, possibilitando agregar valor à biomassa residual que normalmente é descartada. Fazem parte desses resíduos: cascas de frutas, polpas de legumes, folhagens, entre outros; que ao serem utilizados no processamento de diversos segmentos industriais, podem ser fontes valiosas de carboidratos fermentáveis como de prebióticos, utilizados com mais frequência na indústria de alimentos. Essa pesquisa visa descrever a importância da utilização dos produtos residuais agrícolas, com destaque para o principal componente nutritivo, os carboidratos com função prebióticas, bem como, suas possíveis aplicações em diversos processamentos para obtenção de novos produtos biotecnológicos. Os prebióticos são compostos por oligossacarídeos como os gentioligossacarídeos, xiloligossacarídeos, isomaltooligossacarídeo, frutooligossacarídeos e a lactulose, sendo definidos como carboidratos fermentáveis, que ao serem utilizados pela indústria de alimentos, atuam com a capacidade simbiótica de servirem como substrato na fermentação por ação de micro-organismos, que não apresentam toxicidade à saúde humana. Após o desenvolvimento desta pesquisa foi possível observar a importância dos carboidratos fermentáveis no processamento de diferentes produtos com destaque para aqueles oriundos de resíduos agroindustriais.
\end{abstract}

Palavras-Chave: biomassa, biotecnologia, prebióticos, resíduos.

\begin{abstract}
Agricultural residues are considered some of the main possible raw materials for obtaining biological products, making it possible to add value to the residual biomass that is normally discarded. These residues include: fruit peels, vegetable pulps, foliage, among others; that when used in the processing of several industrial segments, they can be valuable sources of fermentable carbohydrates such as prebiotics, used more frequently in the food industry. This research aims to describe the importance of using agricultural waste products, with emphasis on the main nutritional component, carbohydrates with prebiotic function, as well as their

\footnotetext{
${ }^{1}$ Doutoranda em Biotecnologia-Renorbio, Universidade Federal Rural de Pernambuco, nairane.rs@ gmail.com

${ }^{1}$ Doutorado em Biociência animal, Universidade Federal Rural de Pernambuco, quesiajemima0@ gmail.com.br

${ }^{1}$ Mestranda em Biociência Animal, Universidade Federal Rural de Pernambuco, deaquinobeatriz@gmail.com

${ }^{1}$ Doutor, Universidade Federal Rural de Pernambuco, vagne_melo@hotmail.com

${ }^{1}$ Professora Titular, Universidade Federal Rural de Pernambuco, analuporto@ yahoo.com.br
} 
possible applications in various processes to obtain new biotechnological products. Prebiotics are composed of oligosaccharides such as gentioligosaccharides, xyloligosaccharides, isomaltooligosaccharides, fructooligosaccharides and lactulose, being defined as fermentable carbohydrates, which when used by the food industry, act with the symbiotic ability to serve as a substrate in the fermentation by microrganisms that are not toxic to human health. After the development of this research, it was possible to observe the importance of fermentable carbohydrates in the processing of different products, especially those from agro-industrial residues.

Keywords: biomass, biotechnology, prebiotics, waste.

\section{Introdução}

Os resíduos agrícolas são considerados algumas das principais matérias-primas possíveis para obtenção de produtos biológicos (GHOSH et al., 2016), possibilitando agregar valor a biomassa residual que normalmente é descartada (XU et al., 2019). Fazem parte desses resíduos: cascas de frutas, polpas de legumes (GOMES et al., 2016), folhagens, como as das palmeiras, folhas de ervas para preparação de chás, como a camomila, farelo de copra, palhas de arroz (CHIMTONG et al., 2016), e aveia (ROMANÍ et al., 2016) que ao serem utilizados no processamento de diversos segmentos industriais podem ser fontes valiosas de carboidratos fermentáveis, tais como de prebióticos (ROMANÍ et al., 2016), utilizados com mais frequência na indústria de alimentos (GUIDO et al., 2016; ASHWINI et al., 2019).

De acordo com Khangwal et al. (2019), os prebióticos são carboidratos não digeríveis pelo ser humano e, mesmo que não sejam digeridos com facilidade, eles têm uma importante função como a de fibra alimentar (THOMAS et al., 2016); sendo encontrados em vegetais ao serem adicionados no processo ou produzidos a partir da hidrólise enzimática da biomassa lignocelulósica pela indústria alimentícia (GUIDO et al., 2016; KHANGWAL et al., 2019).

Entre os prebióticos estão os oligossacarídeos que são obtidos a partir de diferentes resíduos agrícolas (CHIMTONG et al., 2016), como xilooligossacarídeos (ROMANí et al., 2016), ligninas (KHANGWAL et al.2019), oligossacarídeos de pectina da casca de citros (ZHANG et al., 2018), galacto-oligossacarídeos (WANG et al., 2020), que não são digeríveis pelo organismo humano, porém fornecem substratos que impulsionam o desenvolvimento de microrganismos principalmente no trato gastrointestinal, beneficiando o organismo que os abrigam (HAMASALIM et al., 2016; KERRY et al., 2018), sendo realizado o aproveitamento desses carboidratos, por organismos vivos conhecidos como probióticos (MANO et al., 2018). Prebióticos podem ser utilizados em aditivos e suplemento alimentares (HAMSALIM et al., 2016; TUFARELLI et al., 2016), como na fortificação de sucos de frutas e na fermentação de bebidas não lácteas sendo observada, como uma alternativa para aumentar a ingestão de 
nutrientes bioativos (GOMES et al., 2020), além de sorvetes, ressaltando o sabor (KHANGWAL et al., 2019).

Considerando a busca para suprir as necessidades em reaproveitar os descartes agrícolas, com a necessidade de agregar valor a biomassa, utilizar a biotecnologia e inovação no desenvolvimento de prebióticos se tornou uma alternativa promissora em vários aspectos da saúde humana (FARIAS et al., 2019). Desta forma, o objetivo desta revisão foi descrever a importância da utilização dos produtos residuais agrícolas, com destaque para o principal componente nutritivo, os carboidratos com funções prebióticas, bem como, suas possíveis aplicações em diversos tipos de processamentos alimentícios para obtenção de novos produtos biotecnológicos.

\section{Desenvolvimento}

Para o desenvolvimento desta revisão, foram realizadas pesquisas durante o período de abril de 2020 a julho de 2020, a partir das seguintes plataformas eletrônicas: Science Direct (http://www.sciencedirect.com/), Scielo- ScientificElectronic Library (www.scielo.org) e Springer (https://www.springer.com), utilizando como palavras-chave: biotecnologia e prebióticos, prebióticos dietéticos, resíduos agrícolas, resíduo agroindustrial e resíduo do processamento. Realizou-se a leitura dos títulos e resumos para seleção dos artigos, excluindo os que não estavam dentro do escopo da proposta ou que não detinham informações relevantes para nossa investigação. Foram incluídas publicações em inglês e português que atenderam aos critérios de busca. Foram priorizados artigos com data de publicação entre 2015 e 2020, totalizando 115 publicações, garantindo assim um levantamento bibliográfico atualizado. Para a discussão dos conteúdos investigados, foram abordados os seguintes temas: resíduos agrícolas, prebióticos e suas aplicações biotecnológicas.

\subsection{Resíduos agrícolas}

A agroindústria envolve o conjunto de atividades relacionadas à transformação de matérias-primas, entre elas, as provenientes da agricultura. $\mathrm{O}$ processo de transformação dos produtos alimentícios in natura gera grandes quantidades de resíduos, que se somam a falta de incentivo de políticas públicas, logística e infraestrutura adequada aos pequenos produtores para o escoamento destes, ganhando a cada dia maior importância dentro das empresas (NONES et al. 2016; ORELLANA et al., 2020). 
O descarte inadequado realizado ao ar livre é uma problemática da agroindústria brasileira, que gera potenciais riscos de contaminação dos solos e águas (FAO, 2019; ONG BANCO DE ALIMENTOS, 2019). E a dificuldade de administrar os aterros, que em algumas situações, são os destinos desses resíduos, que em geral não atendem aos padrões ambientais de qualidade, durabilidade limitada, ausência de controle do volume, além de demandarem elevados custos para sua manutenção (MUNHOZ et al., 2019).

A reutilização desses resíduos é a opção mais vantajosa sob o ponto de vista econômico, ambiental, e, muitas vezes, social que representa o descarte inadequado dos resíduos, surgindo um novo olhar através reutilização (VIANA; CRUZ, 2016). Tendo em vista que o reaproveitamento direcionado ao enriquecimento nutricional da alimentação, esses resíduos têm chamado muita atenção por seu efeito direto na saúde pública (MARTINS et al., 2020).

Dentre os maiores volumes de resíduos agrícolas, destacam-se a borra de café (TIAN et al., 2017), as cascas de sementes, as sobras de cortes dos produtos minimamente processados, como melão e melancia; bem como os demais oriundos de fontes variadas (MARTINS et al., 2020), podendo ser utilizados de forma sustentável, contribuindo para agregar valor de consumo, minimizando o desperdício da indústria alimentícia e agrícola, diminuindo, assim, os custos operacionais e sanitários (COSTA FILHO et al., 2017; XU et al., 2019).

\subsection{Prebióticos}

Os prebióticos são elementos, substrato ou ingredientes alimentares, a base de carboidratos não-digeríveis ou estruturas quimicamente estáveis que oferecem uma fonte energética com papel de modular a microbiota intestinal (GARCIA et al., 2016; KHANGWAL et al., 2019), recebendo atenção das indústrias farmacêuticas e alimentícias por seus efeitos benéficos na saúde (GIBSON et al., 2017; FARIAS et al., 2019), como no fortalecimento do sistema imunológico (HAMASALIM et al., 2016 ; KERRY et al., 2018), apresentando elementos utilizados para manter e recuperar a estabilidade de organismos patógenos atuantes em doenças (QUIGLEY et al., 2020), como por exemplo, extratos de folhas de chá impedindo o desenvolvimento de doenças contribuindo para o desenvolvimento e multiplicação de bactérias benéficas (CHIMTONG et al., 2016).

Os prebióticos atuam em distúrbios cardiovasculares, doença de Crohn, esteatose hepática, auxiliando na redução de sintomas referente à má alimentação ou a doença desenvolvida (MENEES et al., 2018; KHANGWAL et al., 2019), na incorporação de cálcio e magnésio, elevando a densidade óssea, minimizando os risco de câncer (ASHWINI et al., 
2019), alergias alimentares (LI et al., 2020), contribuindo para o bem-estar quando acrescentada na ingestão cotidiana, além de serem elementos considerados não calóricos (VENTURA, 2017), demonstrando inúmeras vantagens para o organismo.

Uma característica importante dos prebióticos é a sua capacidade de interagir com os probióticos formando um produto simbiótico com ação importante no intestino delgado e grosso. Na indústria de alimentos essa interação substrato-nutriente é extremamente explorada na produção de bebidas fermentadas por microrganismos (MANO et al., 2018). Os microrganismos classificados como probióticos não apresentam toxicidade à saúde humana (YAHFOUFIET al., 2018). Baseado em indícios, o trato gastrointestinal humano abriga aproximadamente 1014 células bacterianas de diferentes gêneros e espécies (SHA et al., 2020), sendo assim, oferecendo vantagens ao estimular o crescimento e atividade desses microrganismos (HAMSALIM et al., 2016).

Os prebióticos são compostos por oligossacarídeos como os gentioligossacarídeos, xiloligossacarídeos, isomaltooligossacarídeo, frutooligossacarídeos e a lactulose (MADJD et al., 2016), porém a partir da nova definição, outros carboidratos não-digeríveis passam a integrar o grupo de fibras dietéticas (ALVES et al., 2017), como os frutanos (oligofrutose e inulina) que são fibras solúveis e fermentáveis, não digeridas por enzimas hidrolíticas e pela $\alpha$ amilase na parte superior do trato gastrointestinal (CASTRO et al., 2016). Esses compostos são utilizados como prebióticos, por influenciar os processos bioquímicos e físiológicos do organismo, além de agregar características tecnológicas aos alimentos mediante o processamento (OLIVEIRA et al., 2016; ORTEGA et al., 2016).

\subsection{Aplicação Biotecnológica dos prebióticos}

Visando o aumento e melhoria da qualidade de vida, o consumo de alimentos tem sido realizado de forma cada vez mais racional, com a ingestão de alimentos funcionais como os prebióticos (SANTOS et al., 2018; SINGH et al., 2017). A indústria de processamento de alimentos tem adicionado esses compostos em seus produtos visando, também, desenvolver características sensoriais importantes como cor, aroma, textura e sabor; e características tecnológicas, tendo em vista suas propriedades emulsionantes, estabilizadores, agentes de gelificação, edulcorantes (LI et al., 2019), entre outras.

Essas características são obtidas a partir de dois métodos, pela adição oligossacarídeo prebiótico à matriz alimentar, ou pela síntese de carboidrato prebiótico diretamente no produto, por via enzimática (RASTALL; GIBSON, 2015). De acordo com Mano et al. (2018), estudos biotecnológicos estão atuando em possibilidades inovadoras para obtenção de prebióticos a 
partir de fontes de carboidratos, como os oligossacarídeos, através de processos de hidrólise enzimática ou hidrólise ácida de xilanas, encontrada em biomassa lignocelulósica da agroindústria, para aplicação na indústria alimentícia (CHIMTONG et al., 2016; GUIDO et al., 2016). O desenvolvimento de novas técnicas de encapsulamento de prebióticos tem auxiliado muito contra efeitos agressivos ao prebiótico, oferecendo-lhe proteção do meio onde pode se encontrar (CUI et al., 2018; KHANGWAL et al., 2019).

Nissen et al. (2020) desenvolveram uma bebida à base de cânhamo, fermentada com Lactobacillus fermentum, Lactobacillus fermentum plantarum e Bifidubacterium bifidum, que demonstrou ser uma fonte importante de nutrientes, rica em antioxidantes e moléculas bioativas, como os ácidos graxos poli-insaturados. O processo de fermentação pode representar uma estratégia eficaz para aumentar compostos bioativos, como terpenos e acetato, propionato e butirato, provenientes de sementes, como as de cânhamo (GOMES et al., 2020). Os mesmos resultados foram observados por Bessa e Silva (2019) na elaboração e caracterização, físicoquímica e sensorial, de iogurtes de tamarindo enriquecidos com prebióticos (inulina e frutooligossacarídeo), e Gomes et al. (2020) ao adicionar pequi (Caryocar brasiliense) a uma bebida láctea a base de kefir relataram aumento na qualidade tecnológica e nutricional, como adição de compostos antioxidantes, como os carotenóides e aumento da acidez.

De acordo com Feitosa et al. (2019), os fruto-oligossacarídeos também podem ser empregados no processamento substituindo o açúcar, como em sobremesas aeradas de morango, obtendo-se resultados de dulçor muito próximo ao açúcar convencional utilizado pela indústria. Os frutanos podem ser incorporados a alimentos devido às suas propriedades emulsionante e estabilizadora em formulações de massa de pão substituindo açúcar e gordura, apontando a viabilidade e segurança da utilização destes na elaboração de alimentos funcionais (FIGUEIROA; ARRIAGA 2017), demonstrando a tendência que a incorporação desses prebióticos em produtos nutricionais traz benefícios à saúde humana.

Entre os resíduos agrícolas com propriedades prebióticas encontradas, está o grão do café, moído ou simplesmente sua borra (TIAN et al., 2017), assim como, casca de maçãa, farelo de polpa seca do coco, palha de arroz, que ao passar pelo processamento de hidrólise, ocorreu a extração riquíssima em oligossacarídeos utilizado para fins prebiótica e segundo Chimtong et al. (2016), após o processo, houve diferentes concentrações de oligossacarídeos, destacando-se as folhas de chá com maior número de carboidratos, atuando também como antibacteriano em amostras com Escherichia coli. Demonstrando sua alta eficácia como prebiótico e com um bônus em sua atividade, como agente antibacteriano. Conforme pode ser visualizado na tabela 
1, em que exemplificando a potencialidade de utilização da biomassa residual em futuros processos biotecnológicos.

Tabela 1. Relação de subprodutos agrícolas e seus respectivos autores

\begin{tabular}{c|c}
\hline Tipos de resíduos & Referências \\
\hline Casca de Limão e Polpa de beterraba & Gomes et al. (2016) \\
\hline $\begin{array}{c}\text { Casca de Citrus } \\
\text { Cascas: palmeira, maçã, } \\
\text { folhas de chá usadas e café gasto } \\
\text { grãos, farelo de copra e a palha de arroz }\end{array}$ & Chimtong et al. (2016) \\
\hline Palha de aveia & Romaní et al. (2016) \\
\hline Palha de milho e sabugo de milho & Orellana et al. (2020) \\
\hline Casca de trigo & Jagtap et al. (2017) \\
\hline Derivados do leite & Markowiak et al. (2017) \\
\hline $\begin{array}{c}\text { Casca de farelo de arroz, casco de soga } \\
\text { engaço de uva }\end{array}$ & Guido et al. (2016) \\
\hline $\begin{array}{c}\text { Melaço, soro de leite, talos de algodão, } \\
\text { espigas de milho, trigo, palha, madeira de } \\
\text { álamo, bagaço de cana e farinha de copra }\end{array}$ & Mano et al. (2018) \\
\hline Palha de trigo, celulose e lignina & Xu et al. (2019) \\
\hline $\begin{array}{c}\text { Grãos de café torrado, café moído e borra } \\
\text { do café }\end{array}$ & Tian et al. (2017) \\
\hline
\end{tabular}

Fonte: Dados da pesquisa (2020).

A aplicação em nutracêuticos conhecidos como suplementos alimentares também foi evidenciada ao serem extraídos de resíduos agrícolas, como casca de trigo, através do processamento de hidrólise, para obtenção de xilooligossacarídeos e investigação de sua potencialidade antioxidante (JAGTAP et al., 2017), corroborando com a premissa de uso no segmento alimentício. O processo de auto-hidrólise é conhecido como um pré-tratamento que utiliza água sob temperaturas e pressões elevadas favorece a separação inicial do resíduo, conferindo-lhe maior valor agregado da palha de aveia com obtenção de carboidratos como oligossacarídeos e com palha de trigo, celulose e lignina a obtenção de xilooligossacarídeos (ROMANI et al., 2016; CARVALHO 2018; XU et al., 2019), como demonstrado na tabela 2.

Segundo Al-Khalaifa et al. (2019), os probióticos também enriquecem a alimentação animal, respaldados por estudos que indicam que o uso de prebióticos na complementação nutricional de frangos não ocasionam danos ou efeitos colaterais, contribuindo para sua produção. Em organismos humanos, Duarte et al. (2017) relataram que o enriquecimento com pó de caju favorece o desenvolvimento de cepas de micro-organismos como os lactobacillus, considerados probióticos, na indústria alimentícia, conferindo benefícios no crescimento bacteriano. 
Tabela 2. Relação dos tipos de biomassa residual e prebióticos de fonte agrícola

\begin{tabular}{|c|c|c|}
\hline Resíduo & Prebiótico & Referências \\
\hline $\begin{array}{c}\text { Casca de palmeira de } \\
\text { açúcar, casca de maçã de } \\
\text { pinho, folhas de chá usadas } \\
\text { e café gasto } \\
\text { Os grãos, o farelo de copra } \\
\text { e a palha de arroz }\end{array}$ & Oligossacarídeos & Chimtong et al. (2016) \\
\hline $\begin{array}{l}\text { Borra de Café, grão café } \\
\text { moído }\end{array}$ & Oligossacarídeo & Duarte et al. (2017) \\
\hline $\begin{array}{c}\text { Casca de farelo de arroz, } \\
\text { casco de soga engaço de } \\
\text { uva }\end{array}$ & $\begin{array}{c}\text { Oligossacarídeos } \\
\text { galactooligossacarídeo, } \\
\text { frutooligossacarídeo } \\
\text { xilooligossacarideos }\end{array}$ & Guido et al. (2016) \\
\hline $\begin{array}{c}\text { Casca de Limão e Polpa de } \\
\text { beterraba }\end{array}$ & $\begin{array}{c}\text { oligossacarídeos pécticos } \\
\text { Oligogalacturonídeos }\end{array}$ & Gomes et al. (2016) \\
\hline $\begin{array}{l}\text { Melaço, soro de leite, talos } \\
\text { de algodão, espigas de } \\
\text { milho, trigo palha, madeira } \\
\text { de álamo, bagaço de cana e } \\
\text { farinha de copra }\end{array}$ & $\begin{array}{c}\text { Oligossacarídeos: } \\
\text { frutooligossacarídeo, } \\
\text { galactooligossacarídeo, } \\
\text { síntese de } \\
\text { xilooligossacarídeo e de } \\
\text { mananoligossacarídeo }\end{array}$ & Mano et al. (2018) \\
\hline Palha de aveia & $\begin{array}{c}\text { Xilooligossacarídeos } \\
\text { oligossacarídeos e lignina }\end{array}$ & Romaní et al. (2016) \\
\hline $\begin{array}{c}\text { aspargos, beterraba, alho, } \\
\text { chicória, cebola, } \\
\text { alcachofra, trigo, mel, } \\
\text { frutas, vegetais, leite, } \\
\text { sementes de legumes, } \\
\text { lentilhas, ervilhas, feijões, } \\
\text { grão de bico, malva e } \\
\text { mostarda }\end{array}$ & $\begin{array}{c}\text { Galacto-oligossacarídeos } \\
\text { inulina, } \\
\text { frutooligossacarídeos, } \\
\text { oligossacarídeos }\end{array}$ & $\begin{array}{l}\text { Wang et al. (2019) } \\
\text { Wang et al. (2020) }\end{array}$ \\
\hline $\begin{array}{l}\text { Palha de trigo, celulose e } \\
\text { lignina }\end{array}$ & xilooligossacarídeos & Xu et al. (2019) \\
\hline Casca de Citrus & $\begin{array}{c}\text { Oligossacarídeos de } \\
\text { pectina }\end{array}$ & Zhang et al. (2018) \\
\hline
\end{tabular}

Fonte: Dados da pesquisa (2020).

A suplementação com prebióticos objetiva, principalmente, desenvolver características organolépticas e sensoriais nos alimentos e aumentando o valor nutricional destes, realizada em meios contendo microrganismos tem sido de grande importância econômica na produção de alimentos simbióticos (Tabela 3). Segundo Wang et al. (2020) entre os prebióticos com ação simbiótica para o desenvolvimento de microrganismos estão inulina, frutooligossacarídeos e oligossacarídeos, que atuam como substratos para fermentação, conciliando alimentação e saúde, incentivando a indústria alimentícia à inovação no mercado para aplicações futuras 
(FEITOSA et al., 2019). Karimi et al. (2015) demonstraram que a inulina tem um efeito protetor em diferentes cepas de probióticos, aumentando sua sobrevivência e atividade durante o armazenamento. Além de ser resistente à hidrólise, tanto no estômago quanto no intestino delgado, exercendo efeito bifidogênico ligando a uma variedade de propriedades fisiológicas benéficas. É adicionado principalmente a produtos lácteos com baixo teor de gordura, incluindo leite fermentado, iogurte, sobremesa, queijo e sorvete, pois também substitui a gordura (VILLALVA et al., 2017).

Tabela 3. Carboidratos prebióticos com ação simbiótica para o desenvolvimento de probióticos.

\begin{tabular}{|c|c|c|c|}
\hline Prebiótico & Probiótico & Efeito simbiótico & Referências \\
\hline Inulina & Bifidobacterium lactis & $\begin{array}{l}\text { Redução da gordura } \\
\text { em sorvete de } \\
\text { pêssego }\end{array}$ & $\begin{array}{l}\text { Villalva et al. } \\
\text { (2017) }\end{array}$ \\
\hline$\beta$-glucano & $\begin{array}{c}\text { Lactobacillus e } \\
\text { Bifidobacterium spp. }\end{array}$ & $\begin{array}{l}\text { Redução da gordura } \\
\text { em iogurte }\end{array}$ & $\begin{array}{c}\text { Ibrahim; Seleneva } \\
\text { (2019) }\end{array}$ \\
\hline Inulina & $\begin{array}{c}\text { Lactobacillus acidophilus } \\
\text { LA-5 e Bifidobacterium lactis } \\
\text { BB-12 }\end{array}$ & $\begin{array}{l}\text { Leite fermentado } \\
\text { com baixo teor de } \\
\text { gordura }\end{array}$ & $\begin{array}{l}\text { Pereira et al. } \\
\qquad(2020)\end{array}$ \\
\hline Inulina & Lactobacillus rhamnosus SP1 & $\begin{array}{l}\text { Bebida fermentada a } \\
\text { base de água de coco }\end{array}$ & $\begin{array}{l}\text { Segura-Badilla et } \\
\text { al. (2020) }\end{array}$ \\
\hline$\beta$-glucano & $\begin{array}{l}\text { Streptococcus thermophillus, } \\
\text { Lactobacillus bulgaricus } \mathrm{e} \\
\text { Lactobacillus acidophilus }\end{array}$ & $\begin{array}{l}\text { Iogurte fermentado } \\
\text { de leite de búfala }\end{array}$ & $\begin{array}{l}\text { Sinamo; Hasan; } \\
\text { Hasanah (2019) }\end{array}$ \\
\hline Inulina & $\begin{array}{l}\text { Lactobacillus acidophilus, } \\
\text { Estreptococo termofílico e } \\
\text { Acidophilus bacillus }\end{array}$ & $\begin{array}{l}\text { Bebida fermentada a } \\
\text { base de leite de aveia }\end{array}$ & $\begin{array}{l}\text { Sukhova et al. } \\
\text { (2020) }\end{array}$ \\
\hline
\end{tabular}

Fonte: Dados da pesquisa 2020.

Em preparos de bebidas à base de vegetais, além da soja e arroz, o cânhamo vem sendo empregado como um substituto inovador ao leite de origem animal (NISSEN et al., 2020). Na tabela 4 é possível observar as principais aplicações biotecnológicas entre outras diferentes fontes prebióticas.

Tabela 4. Aplicações biotecnológicas de prebióticos.

\begin{tabular}{c|c|c}
\hline Prebiótico & Aplicação tecnológica & Referências \\
\hline $\begin{array}{c}\text { Frutooligossacarídeo } \\
\text { (FOOS) }\end{array}$ & Fermentação de embutidos & Bis-Souza et al. (2020) \\
& & Bis-Souza; Penna; Barretto \\
& & (2020) \\
& & Feitosa et al. (2019) \\
& Figueiroa; Arriaga (2017) \\
& Tewari et al. (2018) \\
\hline
\end{tabular}




\begin{tabular}{c|c|c}
\hline $\begin{array}{c}\text { Xilana } \\
\text { (xilooligossacarídeo) }\end{array}$ & Clarificação de sucos & $\begin{array}{c}\text { Rosmine et al. (2017); } \\
\text { Shahrestani et al. (2016) }\end{array}$ \\
\hline $\begin{array}{c}\text { Inulina } \\
\begin{array}{c}\text { Quitooligossacarídeos } \\
\text { (COS) }\end{array}\end{array}$ & $\begin{array}{c}\text { Iogurte tipo grego } \\
\text { Bebidas à base de soro de } \\
\text { leite }\end{array}$ & $\begin{array}{c}\text { Costa et al. (2019) } \\
\text { Munhoz et al. (2019) } \\
\text { Tewari et al. (2018) }\end{array}$ \\
\hline Galactooligossacarídeo & $\begin{array}{c}\text { Redução de lactose em } \\
\text { bebidas lácteas }\end{array}$ & $\begin{array}{c}\text { Gallina et al. (2019) } \\
\text { Tewso et al. (2019) }\end{array}$ \\
\hline
\end{tabular}

Fonte: Dados da pesquisa 2020.

Buscando ser mais atrativo ao consumidor, a indústria de laticínios vem adicionando polpa ou pedaços de frutas em iogurtes e compostos com função de prebiótico. Munhoz et al. (2019) ao adicionar fibras e polpa de açaí (Euterpe oleracea) a bebida fermentada, relataram uma melhor aceitação sensorial e nutricional, tendo em vista o teor de antocianinas, composto antioxidante de cor avermelhadas e de sólidos solúveis totais presentes na fruta, importantes para saúde humana. No entanto, os prebióticos também são empregados, na produção de diversas bebidas, como os chás. Segundo Tewari et al. (2018) relatam a eficiência na melhoria da qualidade nutricional e sensorial de chá verde, gelado, pronto para ingestão (RTD) adicionado dos galactooligossacarídeo (GOS), frutooligossacarídeo (FOS) e inulina e ingredientes simbióticos (GOS, FOS, inulina e Lactobacillus acidophilus).

\section{Considerações Finais}

Apesar dos problemas ambientais atribuídos aos resíduos agroindustriais, esses têm demonstrado ser uma excelente fonte de nutrientes para ser utilizado como substrato em processos fermentativos, o que os tornam atrativos, principalmente, para a indústria de processamento de alimentos e bebidas, por serem ricos em carboidratos fermentáveis com atividade prebiótica. Os prebióticos quando adicionados nos alimentos podem auxiliar nas suas características organolépticas e contribuir para o desenvolvimento de micro-organismo probióticos benéficos ao organismo humano. Com isso os prebióticos tornam-se uma alternativa viável para a produção de compostos funcionais, agregando valor econômico a esses produtos. 


\section{Referências}

AL-KHALAIFA, H.; AL-NASSER, A.; AL-SURA YEE, T.; AL-KANDARI, S.; AL-ENZI, N.; AL-SHARRAH, T.; RAGHEB, G.; AL-QALAF, S.; MOHAMMED, A. Effect of dietary probiotics and prebiotics on the performance of broiler chickens. Poultry science, v. 98, n. 10, 2019.

ALVES, A.P.C.; MARQUES, T.R.; CARVALHO, T.C.L.; PINHEIRO, A.C.M.; RAMOS, E.M.; CORRÊA, A.D. Elaborationandacceptabilityofrestructuredhamsaddedwith jabuticaba skin. Food Science Technology, v. 37, n. 2, 2017.

ARRUDA, H.S.; PEREIRA, G.A.; PASTORE, G.M. Oligosaccharide profile in Brazilian Cerrado fruit araticum (Annona crassiflora Mart.). Lebensmittel-Wissen schaftund Technologie. Food Science and Technology, n. 76, 2017.

BIS-SOUZA, C.V.; PATEIRO, M.; DOMÍNGUEZ, R.; PENNA, A.L.B.; LORENZO, J. M.; BARRETTO, A.C.S. Impacto fructooligosaccharides and probiotics trains on the quality parameters of low-fat Spanish Salchichón. Meat Science, n.159, 2020.

BIS-SOUZA, C.V.; PENNA, A.L.B.; BARRETTO, A.C.S. Applicability of potentially probiotic Lactobacillus casei in low-fat Italian type salami withad ded fructooligosaccharides: in vitro screening and technological evaluation. Meat Science, n.168, 2020.

BONGAERTS, G.P.A.; SEVERIJNEN, R.S.V.M. A reassessment of the PROPATRIA study and its implications for probiotic therapy. Nature biotechnology, v. 34, n. 1, 2016.

CASTRO, N.L.M.; AMBROSIO, G.P.; VIERA, L.C.; VELEZ, A.E.; BRAVO, V.B. Diseño de una bebida potencialmente funcional de tomate (Lycopersicum esculentum) con tumeric (Curcuma longa Linn). Cumbres, v. 2, n. 2, 2016.

CHIMTONG, S.; SAENPHOOM, P.; KARAGEAT, N.; SUTTAY, S. Oligosaccharide production from agricultural residues by non starch polysaccharide degrading enzyme sand their prebiotic properties. AgricultureandAgricultural Science Procedia, v. 11, p. 131-136, 2016.

COSTA, M.F.; PIMENTEL, T.C.; GUIMARÃES, J.T.; BALTHAZAR, C.F.; ROCHA, R.S.; CAVALCANTI, E.A.; ESMERINO, M.Q.; FREITAS, R.S.L.; RAICES, M.C.; SILVA, A.C.; CRUZ, I. Impacto prebiotics on ther geological characteristic sand volatil e compounds of Greek yogurt. LWT, n.105, 2019.

COSTA FILHO, D. V. et al. Aproveitamento de resíduos agroindustriais na elaboração de subprodutos. In: II Congresso Internacional das Ciências Agrárias-COINTER-PDVAgro. 2017.

CUI, Yuanjing et al. Photonic functional metal-organic frameworks. Chemical Society Reviews, v. 47, n. 15, p. 5740-5785, 2018.

FAO, Fisheries Department, Rome, Italy (2018) 
FARIAS, D.P.; ARAÚJO, F.F.; NERI-NUMA, I.A.; PASTORE, G.M. Prebiotics: trends in food, heal thand technological applications. Trends in food science \& technology, v. 93, 2019.

FEITOSA, B.F.; FONTES, C.P.M.L.; OLIVEIRA, E.N.A.; MACHADO, A.L.; NETO, J.O.O.; FEITOSA, J.V.F. Prebiotics fructooligosaccharides as a substitute for commercial sugar in aerated strawberry desserts with a non-dairy matrix. Revista Verde, v.14, n.4, 2019.

FIGUEROA ARRIAGA, I. C. Obtención de un producto de panificación enriquecido con fructanos de Agave angustifolia Haw y su evaluación en ratones en crecimiento. 2017. 96 f. Tesis (Maestría em Ciencias em Desarrollo de Productos Bióticos)Centro de Desarollo de Productos Bióticos, Instituto Politécnico Nacional, Morelos, 2017.

GALLINA, D.A.; PACHECO, M.T.B.; BARBOSA P.P.M.; AMORIM, M.M.F.; COBAS, A.C. Efeito de quito-oligosacarídeos modificados nas características físico-químicas e microbiológicas em uma bebida probiótica fermentada. Revista do Instituto Laticínios Cândido Tostes, v. 74, n. 4, 2019.

GARCIA MARIÑO, A.; NÚÑEZ VELÁZQUEZ, M.; BARRETO PENIÉ, J. Microbiota, probióticos, prebióticos y simbióticos. Acta Médica de Cuba, v. 17, n. 1, 2016.

GHOSH, S.; CHOWDHURY, R.; BHATTACHARYA, P. Sustainabilityof cereal straws for thefermentativeproductionofsecondgenerationbiofuels: a review oftheefficiencyandeconomicsofbiochemicalpretreatment processes. Applied Energy, v. 198, 2017.

GIBSON, Glenn R. et al. Expert consensus document: The International Scientific Association for Probiotics and Prebiotics (ISAPP) consensus state menton the definition and scope of prebiotics. Nature reviews Gastroenterology \& hepatology, v. 14, n. 8, p. 491, 2017.

GOMES, F.O.; SILVA, M.C.M.; SOUZA, P.B.; FREITAS, T.K.T.; SILVA, D.J.S. Physical and chemical evaluation of a pequi taste kefir drink. Brazilian Journal of Development, v. 6, n. 3, 2020.

GRANATO, D.; BARBA, F.J.; KOVA, D.B.; LORENZO, J.M.; CRUZ, A.G.; PUTNIK, P. Functional Foods: Product Development, Technological Trends, Efficacy Testing, and Safety. Annual Review of Food Science and Technology, v.20, 2019.

GUIDO, E.S.; KALIL, S.J.; DA SILVEIRA, J.T. Produção de xilo-oligossacarídeos por hidrólise enzimática de xilana de madeira de faia. Anais do Salão Internacional de Ensino, Pesquisa e Extensão, v. 7, n. 4, 2016.

GUIMARÃES, J.T.; SILVA, E.K.; COSTA，A.L.R.; CUNHA，R.L.; FRITAS, M.Q.; MEIRELES, M.A.A.; CRUZ, A.G. Manufacturing a prebiotic whey beverageexploringtheinfluenceofdegreeofinulinpolymerization. Food Hydrocolloids, v.77, 2018.

GUERIN, J.; PETIT, J.; BURGAIN, J.; BORGES, F.; BHANDARI, B.; PERROUD, C.; DESOBRYA, S.; GIANI, J.C. Lactobacillus rhamnosus GG encapsulation by spray drying: milk proteins clotting control to produce innovative matrices. Jounal Food Engineering, $\mathrm{n}$. 193, 2017. 
HAMASALIM, H.J. Synbiotic como aditivos alimentares relacionados à saúde e desempenho animal. Avanços em Microbiologia, v.6, n.4, 2016.

HOSEINIFAR, S.H.; AHMADI, A.; RAEISI, M.; HOSEINI, S.H.; KKHALILI, M.; BEHNAMPOUR, N. Comparative study on immuno modulatory and grow then hancing effects of three prebiotics (galactooligosaccharide, fructooligosaccharide and inulin) in common carp (Cyprinuscarpio). Fish Shell fish Immunol, n.58, 2016.

HOSSAIN, M.I.; SADEKUZZAMAN, M.; HA, S.D. Probiotics as potential alternative biocontrol agents in the agriculture and food industries: A review. Food Research International, v.100, 2017.

IBRAHIM, M.N.G.; SELEZNEVA, I.S.The symbiotic effecto foat $\beta$-glucanenrichingbiolowfat yogurt. Научныйжурнал НИУ ИТМО, n.4, 2019.

JAGTAP, Sandeep; RAHIMIFARD, Shahin. Unlock ing the potential of the Internet of Thingsto improve resource efficiency in food supply chains. In: International Conference on Information and Communication Technologies in Agriculture, Food \& Environment. Springer, Cham, 2017. p. 287-301.

KERRY, R.G.; PATRAB, J.K.; YOOHEON, S.G.; HAN-SEUNG, P.; DAS, S. Benefaction of probiotics for human health: A review. Journal of food and drug analysis, v. 26, n. 3, 2018.

KARIMI, R.; AZIZI, M.H.; GHASEMLOU, M.;Vaziri, M. Application of inulin in cheese as prebiotic, fat replacer and texturizer: a review.Carbo hydrate Polymers, v.119, 2015.

KHANGWAL, I.; SHUKLA, P. Potential prebiotics and their transmission mechanisms: Recent approaches. journal of food and drug analysis, v. 27, n. 3, p. 649-656, 2019.

KOBYLIAK N, C.C.; CAMMAROTA, G.; HALEY, A.P.; STYRIAK, I.; GASPAR, L.; et al. Probiotics in prevention and treatment of obesity: a critical view. Nutr Metab, v. 13, 2016.

LI, N.; WANG, Z. QU, T.; KRAFT, J.; OH, J.; PIJKEREN, J.P.; HUBER, G.W.; PAN, X. High yield synthesis of glucooligosaccharides (GlOS) as potential prebiotics from glucose: Via non enzymatic glycosylation. Green Chemistry, v. 21, n. 10, p. 2686-2698, 2019.

MANO, Mario Cezar Rodrigues et al. Oligosaccharide biotechnology: an approach of prebiotic revolution on the industry. Applied microbiology and biotechnology, v. 102, n. 1, p. 17-37, 2018.

MADJD, A., TAYLOR, M.A., MOUSAVI, N.; DELAVARI, A.; MALEKZADEH, R.; MACDONALD, I.A.; FARSHCHI, H.R. Comparison of the effect of daily consumption of probiotic compared with low-fat conventional you gurton weightloss in heal thy obese women following na energy-restricted diet: a randomized controlled trial. The American Journal of Clinical Nutrition, v.103, n.2, 2016.

MARKOWIAK, Paulina; ŚLIŻEWSKA, Katarzyna. Effects of probiotics, prebiotics, and synbiotics on human health. Nutrients, v. 9, n. 9, p. 1021, 2017. 
MARTINS, L.H.S.; KONAGANO, E.M.H.; SOUZA, R.L.L.S.; LOPES, A.S. Physicochemical analysis of different agro-industrialresidues for its use in thein dustry. Brazilian Journal of Development, v. 6, n. 2, 2020.

MENEES, S.; CHEY, W. The gut microbio me and irritable bowel syndrome. F1000. Research, v. 7, 2018.

MUNHOZ, C.L.; HIRATA, V.G.; FRIA, S.B.; FERREIRA, T.H.B. Elaboração de iogurtes de açaí (Euterpe oleracea) com adição de prebióticos. Global Science Technology, v.12, n.3, 2019.

NUNES, P.B.B.; ANDRADE, S.A.C.; SILVA, T.M.S.; SILVA, G.R.; MACHADO, E.C.L. Prebiotics kimmed UHT milk: advances in enzimatic conversion of lactose to galactooligosaccharides. Brazilian Journal of Development, v. 6, n. 5, 2020.

NISSEN, L.; CARLO, E.; GIANOTTI, A. Prebiotic potential of hemp blended drinks fermented by probiotics. Food Research International, n. 131, 2020.

NONES, D.L.; BRAND, M.A.; AMPESSAN, C.G.M.; FRIDERICHS, G. Quantification of agricultural and forestry waste biomass to production of compacts for power generation. Revista de Ciências Agroveterinárias, v.16, n.2, 2017

ORELLANA, B.B.M.A.; VALE, A.T.; ORELLANA, J.B.P.; CHAVES, B.S.A.; MOREIRA, A.C.O. Caracterização de resíduos de resíduos agroindustriais da região do distrito federal para fins energéticos. Energia na agricultura, v. 35, n. 1, p. 46-61, 2020.

OLIVEIRA, C.F.D.; PINTO, E.G.; TOMÉ, A.C.; QUINTANA, R.C.; DIAS, B.F. Desenvolvimento e caracterização de geleia de laranja enriquecida com aveia. Revista de Agricultura Neotropical, v. 3, n. 3, 2016.

ORTEGA, M.; BARBOZA, Y.; PIÑERO, M.P.; PARRA, K. Formulación y evaluación de una galleta elaborada con avena, linaza y pseudofruto del caujil como alternativa de un alimento funcional. Multiciencias, v. 16, n. 1, 2016.

PEREIRA, J.A.; PINTO, S.S.; DIAS, C.O.; VIEIRA, M.P.T.; RIBEIRO, D.H.B.; AMBONI, R. D.M.C.; FRITZEN-FREIRE, C.B. Potentially symbiotic fermented milk: A preliminary approach using lactose free milk. Food Science and Technology, https://doi.org/10.1016/j.lwt.2019.108847, 2020.

RASTALL, R.A.; GIBSON, G.R. Recent developments in prebiotics to selectively impact beneficial microbes and promote intestinal health. Current Opinion in Biotechnology, v. 32, p. 42 46, 2015.

ROMANÍ, A., TOMAZ, P.D., GARROTE, G., TEIXEIRA, J., DOMINGUES, L. Combined álcali and hydro thermal pre treatments for oatstraw valorization within a biorefinery concept. Bioresource. Technology, v. 220, 2016.

ROSMINE, E.; SAINJAN, N.C.; SILVESTER, R.; ALIKKUNJU, A.; VARGHESE, S.A. Statistical optimisation of xylanase production by estuarine Streptomyces sp. and its application 
in clarification of fruit juice. Journal of Genetic Engineering and Biotechnology, v. 15, n. 2, p. 393-401, 2017.

SHAHRESTANI, H.; TAHERE-KAFRANI, A.; SOOZANIPOUR, A.; TAVAKOLI, O. Enzymatic clarification of fruit juices using xylanase immobilized on 1, 3, 5-triazinefunctionalized silica-encapsulated magnetic nanoparticles. Biochemical engineering journal, v. 109, p. 51-58, 2016.

SEGURA-BADILLA, O.; LAZCANO-HERNÁNDEZ, M.; KAMMAR-GARCÍA, A.; VERALÓPEZ, O.; AGUILAR-ALONSO, P.; RAMÍREZ-CALIXTO, J.; NAVARRO-CRUZ, A.R. Use of coconutwater (Cocus nucifera $L$ ) for the development of a symbiotic functional drink. Heliyon, v.6, 2020.

SINAMO, K.N.; HASAN, F.; HASANAH, U. Effect of concentration starter and fermentation time on the quality of yoghurt drink from buffalo milk. Journal of Physics: Conference, n.1542, 2020.

SANTOS, R.O.; SILVA, M.V.F.; NASCIMENTO, K.O.; BATISTA, A.L.D.; MORAES, J.; ANDRADE, M.M.; ANDRADE, L.G.Z.S.; KHOSRAVI- DARANI, K.; FREITAS, M.Q.; RAICES, R.S.L.; SILVA, M.C.; JUNIOR, J.L.B.; BARBOSA, M.I.M.J.; CRUZ, B.A.G. Prebiotic flours in dairy food processing: Technological and sensory implications. International Journal of Dairy Technology, v. 71, 2018.

SINGH, S.P.; JADAUN, J.S.; NARNOLIYA, L.K.; PANDEY, A. Pandey Prebiotic Oligosaccharides: Special Focus on Fructooligosaccharides, Its Biosynthesis and Bioactivity. Applied Biochemistry and Biotechnology, v. 183, n. 2, 2017.

SUKHOVA, I.V.; ROMANOVA, T.N.; KOROSTELEVA, L.A.; BAIMISHEV, R.H.; DOLGOSHEVA, E.V. The effect of hydrated oatmeal on quality of the symbiotic fermented milk product. BIO Web of Conferences, n.17, 2020.

THAVARAJAH, D.; THAVARAJAH, P.; ABARE, A.; BASNAGALA, S.; LACHER, C.; COMBS JR, P.S.G.F. Mineral micronutrient and prebiotic carbohydrate profiles of USAgrownkale (brassicaoleracea L. var. acephala). Journal of Food Composition and Analysis, v. 52, p. 9-15, 2016.

THOMAS, L.V. Probiotics-the journey continues. International Journal of Dairy Technology, v.69, 2016.

TEWARI, S.; DUBEY, K.K.; REKHA, S. Evaluation and application of prebiotic and probiotic ingredients for development of ready to drink tea beverage. Journal of food science and technology, v. 55, n. 4, p. 1525-1534, 2018.

TIAN, T.; LIU, Y.; YAN, H.; YOU, Q.; YI, X.; DU, Z.; XU, W.; SU, Z.. Analysis tool kit for the agricultural community. Nucleic acids research, v.45, n.W1, p. W122-W129, 2017.

TUFARELLI, V.; LAUDADIO, V. An overview on the functional food concept: prospectives and applied researches in probiotics, prebiotics and synbiotics. Journal of Experimental Biology and Agricultural Sciences, n. 4, 2016. 
VENTURA, E. Consumption of probiotic compared with low-fat conventional yougurt on weight loss in. Disponível em:<http://g1.globo.com/mg/zona-da-mata/blog/casal-fit-no-g1zona-da-mata/post/alimentos-prebioticos.html.> Acesso em: 21 de jul 2020

VILLALVA, F.J.; BRUNERI, A.P.C.; VINDEROLA, G.; OLIVEIRA, E.G.; PAZ, N. F.; RAMÓN, A.N. Formulation of a peach ice cream as potential symbiotic food. Food Science and Technology, v. 37, n. 3,2017.

VIANA, L.G.; CRUZ, P.S. Reaproveitamento de resíduos agroindustriais. In: IV Congresso Baiana de Engenharia Sanitária e Ambiental, 2016.

WANG, S.; XIAO, Y.; TIAN, F.; ZHAO, J.; ZHANG, H.; ZHAI, Q.; CHEN, W. Rational use of prebiotics for gut microbiota alterations: Specific bacterial phylotypes and related mechanisms. Journal of Functional Foods, v. 66, p. 103838, 2020.

WANG, Y.; GUO, Q.; DOUGLAS, G.; H., LAPOINTE, G. Oligosaccharides: Structure, function and application. Encyclopedia of Food Chemistry, 2019.

XIA, Y.; WANG, M.; GAO, F.; LU, M.; CHEN, G. Effects of dietary probiotic supplementation on the growth, gut health and disease resistance of juvenile Nile tilapia (oreochromisniloticus). Animal Nutrition, v. 6, n. 1, 2020.

XU, J.; LIU, B.; WU, L.; HU, J.; HOU, H.; YANG, J. A waste-minimized biorefinery scenario for the hierarchical conversion of agricultural straw into prebiotic xylooligosaccharides, fermentable sugars and lithium-sulfur batteries. Industrial Crops and Products, v. 129, 2019.

YAHFOUFI, N.; MALLET, J.F.; GRAHAM, E.; MATAR, C. Role of probiotics and prebiotics in immunomodulation. Curr Opin Food Sci, v.20, 2018. 